\title{
Allergy Prevalence in France and Skin Impact - Epidemiological Survey of a Representative Sample of French Adults
}

\author{
Sophie Seité (ID) \\ Charles Taieb (iD ${ }^{2}$ \\ Nhân Pham-Thi ${ }^{3,4}$ \\ Annick Barbaud ${ }^{5,6}$
}

'La Roche-Posay Dermatological Laboratories, Levallois-Perret, France;

${ }^{2}$ European Market Maintenance Assessment, Fontenay-sous-Bois, France; ${ }^{3}$ Ecole Polytechnique, Economics, Palaiseau, France; ${ }^{4}$ Institut Pasteur Paris, Allergology, Paris, France; ${ }^{5}$ Dermatology and Allergy Department, Tenon Hospital, Medicine Sorbonne University, Paris, France; ${ }^{6}$ Assistance Publique-Hôpitaux de Paris, Paris, France
Correspondence: Sophie Seité

La Roche-Posay Dermatological Laboratories, 62 Quai Charles Pasqua,

Levallois-Perret, 92300, France

Tel +33 I 49643340

Email sophie.seite@loreal.com
Background: Increased allergy frequency may have a significant impact on the skin, one of the largest targeted organs for allergic and immunological responses.

Methods: An online survey of 2036 adults as a representative sample of the French general population was conducted to evaluate the prevalence of self-reported allergies, the populations who report allergies and the skin conditions related to allergies.

Results: In general, $20.2 \%$ of French adults (average age $45 \pm 15.8$ years) reported allergies. These allergies were respiratory allergies (55.3\%), skin allergies (48.8\%) and food allergies (27.9\%), and $78.9 \%$ indicated that their reported allergies were diagnosed by a doctor. In addition, $53.2 \%$ of individuals reporting an allergy also indicated that they experienced associated skin reactions. In comparison to those who did not report an allergy, these individuals were 1.5 to 4 times more likely to have a skin disease and 3 times more likely to have sensitive skin or skin reactions when using skincare products.

Conclusion: It is estimated that over 10 million French adults have allergies. These data will help increase awareness among the allergic population and healthcare professionals about the burden associated with allergies and the need for management to reduce their health impact.

Keywords: allergies, food allergy, skin allergy, respiratory allergy, prevalence, skin side effects

\section{Introduction}

The frequency of allergies has been on the rise in the Western world. This phenomenon is called the "allergy epidemic". 1

These allergic diseases (eczema, hay fever, asthma and rhinitis) in children often present as heterogeneous phenotypes, but they have common patterns, such as hyperimmune reactivity and epithelial porosity, with the most well-known genetic example being filaggrin deficiency in the epidermis. ${ }^{2}$ The negative effects of air pollution on the skin have also been described, mainly in eczema lesions. ${ }^{3}$

There are few data available on the French population and the occurrence of allergic features. Furthermore, this is the first survey that accounts for the perceptions of patients suffering from an allergy or eczema about the environment's role in their skin diseases.

\section{Methods}

Study Population

An online survey was conducted in March 2019 by a polling institute (HC Conseil, Paris, France) after recruitment of a sample of the general French adult 
Table I Quota Used to Select the Study Population (INSEE)

\begin{tabular}{|c|c|c|}
\hline \multirow[b]{2}{*}{ Sex and Age Breakdown } & \multicolumn{2}{|c|}{ INSEE } \\
\hline & Males & Females \\
\hline 18-24 years old & $6.0 \%$ & $6.0 \%$ \\
\hline $25-34$ years old & $8.0 \%$ & $9.0 \%$ \\
\hline $35-44$ years old & $9.0 \%$ & $9.0 \%$ \\
\hline $45-54$ years old & $10.0 \%$ & $10.0 \%$ \\
\hline $55-64$ years old & $9.0 \%$ & $9.0 \%$ \\
\hline 65-74 years old & $7.0 \%$ & $8.0 \%$ \\
\hline \multicolumn{3}{|l|}{ Regional Distribution } \\
\hline Ile de France & \multicolumn{2}{|c|}{$19 \%$} \\
\hline Northwest & \multicolumn{2}{|c|}{$23 \%$} \\
\hline Northeast & \multicolumn{2}{|c|}{$23 \%$} \\
\hline Southwest & \multicolumn{2}{|c|}{$11 \%$} \\
\hline Southeast & \multicolumn{2}{|c|}{$24 \%$} \\
\hline \multicolumn{3}{|l|}{ Socio-Professional Status } \\
\hline Superior & \multicolumn{2}{|c|}{$23 \%$} \\
\hline Lower & \multicolumn{2}{|c|}{$27 \%$} \\
\hline Inactive & \multicolumn{2}{|c|}{$50 \%$} \\
\hline
\end{tabular}

population over 18 years of age. To provide a population representative of the general French adult population, proportional quotas were used based on sex, age, socioeconomic status, and regional distribution (as described in Table 1) according to data previously published by INSEE.

Collected data were obtained via the Internet from a random selection of 2036 French Internet users over 18 years old who agreed to participate. An Internet questionnaire was completed by each participant, but if contact was lost or the questionnaire was not totally completed, another participant with similar characteristics (sex, age, socioeconomic status, and regional distribution) was selected. No missing data were allowed, and respondents had to answer all questions.

However, before answering the questionnaire, each respondent was informed of the nature of the survey, that their anonymity would be respected, and that collected information would not allow identification. Each respondent had to confirm his or her agreement and nonopposition to answer the questionnaire. This research used anonymous data without direct patient contact, and institutional review board approval was not necessary prior to the study initiation; nevertheless, this survey was conducted in accordance with the Declaration of Helsinki, General Data Protection Regulation or GDPR policies were followed during the questionnaire administration, in accordance with French legislation.

\section{Survey}

An online questionnaire was completed, which included a range of sociodemographic questions related to gender, age, profession, social class, area of residence, and smoking habits as well as skin type [following Fitzpatrick classification with descriptive pictures], occurrence and type of allergies, known allergens, medical diagnosis, therapeutic treatment, symptoms, skin side effects, skin sensations such as tingling, burning, tautness, itching or pain, symptoms and environmental impact factors, such as exposure to pollution or sun.

The filter question was "Do you think you are allergic?" In the event that the responder self-reported being allergic, they were asked whether a doctor had confirmed the diagnosis. The subject was then questioned to determine if it was a respiratory, food or skin allergy. Drug allergies, which have a different mechanism, were not investigated.

\section{Statistical Analysis}

In this descriptive study, participants who reported allergies were compared to participants who did not report any allergies. Quantitative variables are expressed as the mean and standard deviation. Qualitative variables are expressed as frequencies and percentages. Comparisons between groups were performed using Student's $t$-test in the case of quantitative variables. For categorical variables, intergroup comparisons were conducted using the $\chi^{2}$ test. Relative risk (RR) was calculated to compare the population who reported allergies to the population who did not report allergies. The level of significance was set at $5 \%$. Statistical analyses were performed using R software version 3.6.1 (Vienna, Austria).

\section{Results}

\section{Global Representative Population}

Out of the 2036 French respondents (18 to 74 years old, $48.9 \%$ male and $51.1 \%$ female), $20.2 \%$ of subjects (mean age $45 \pm 15.8$ years) self-reported having at least one allergy (of which $42.7 \%$ were men and $57.3 \%$ women). Overall, $44.3 \%$ of the total population lived in rural areas ( $<20,000$ inhabitants), $30.3 \%$ in suburban areas or medium-size cities (between 100,000 and 20,000 inhabitants), and $25.4 \%$ in large cities $(>100,000$ inhabitants $)$, and $24.8 \%$ were smokers. The phototype repartitions of the global studied population were $13.1 \%, 37 \%, 38 \%, 9.1 \%$, $1.7 \%$, and $1.2 \%$ for phototypes I to VI, respectively. In this 
Table 2 Doctors Who Diagnosed Allergies

\begin{tabular}{|l|c|c|}
\hline & $\mathbf{n}$ & $\%$ \\
\hline Participants Reporting an Allergy & $\mathbf{4 I 2}$ & $\mathbf{2 0 . 2 4 \%}$ \\
Subjects able to name the allergy & 228 & $55.34 \%$ \\
\hline Percentage of Participants Diagnosed by & $\mathbf{3 2 5}$ & $\mathbf{7 8 . 8 8} \%$ \\
A Doctor & & \\
\hline Health professional who diagnosed the allergy & & \\
General Practitioner & 154 & $47.38 \%$ \\
Allergy specialist & 93 & $28.62 \%$ \\
Dermatologist & 60 & $18.46 \%$ \\
Pulmonary practitioner & 10 & $3.08 \%$ \\
Other specialized physician & 4 & $1.23 \%$ \\
Otolaryngologist & 3 & $0.92 \%$ \\
Acupuncturist & 1 & $0.31 \%$ \\
\hline
\end{tabular}

Abbreviation: $n$, number of participants.

French population, approximately $30 \%$ of the respondents reported dry skin, which corresponds to the prevalence usually found in this country.

The reported allergies included respiratory allergies (55.3\%), skin allergies (48.8\%) and food allergies (27.9\%). Overall, $78.9 \%$ of the French respondents reported that their allergies had been diagnosed by at least one practitioner, who was a general practitioner in most of the cases and an allergist or a dermatologist in others (Table 2). However, many French respondents selfreported not using any treatment (corticosteroids, antihistamines, or other): $44.7 \%, 59.2 \%$ and $63.5 \%$ of those with respiratory, skin and food allergies, respectively.

Additionally, 55.3\% were able to identify the allergen(s) responsible for their allergies (mainly pollen and dust mites), as well as the main symptoms associated with their allergies, including allergic rhinitis, eczema, or asthma (Table 3).

Overall, $53.2 \%$ of those who reported allergies also had associated skin reactions. Among them, a practitioner diagnosed their skin diseases in $60.3 \%$ of cases, and $34.7 \%$ had to use topical and/or oral treatments (Table 4).

\section{Allergic Population versus Non-Allergic Population}

Compared to the population who did not report an allergy, the population who reported allergies included more females $(57.3 \%)$ than males $(49.59 \%)(\mathrm{p}=0.0057)$, without significant differences concerning living in large cities $(29.1 \%$ for those who were allergic vs $24.5 \%$, NS) or their habit of smoking $(22.8 \%$ vs $27.2 \%$, NS).
Table 3 Symptoms and Allergens Related by the Allergic Population

\begin{tabular}{|l|c|c|}
\hline $\begin{array}{l}\text { Symptoms Associated with Allergy Reported } \\
\text { by Participants }\end{array}$ & $\mathbf{n}$ & $\%$ \\
\hline Allergic rhinitis (hay fever) & 202 & $49.03 \%$ \\
Eczema/atopic dermatitis & 124 & $30.10 \%$ \\
Asthma & 102 & $24.76 \%$ \\
Conjunctivitis & 89 & $21.60 \%$ \\
Other & 82 & $19.90 \%$ \\
Bronchitis with wheezing & 41 & $9.95 \%$ \\
Edema & 29 & $7.04 \%$ \\
\hline Allergens Reported by Participants & $\mathbf{n}$ & $\%$ \\
\hline Pollens & 231 & $56.07 \%$ \\
Dust mites & 142 & $34.47 \%$ \\
Other & 87 & $21.12 \%$ \\
Dogs, cats, ferrets, other animals & 78 & $18.93 \%$ \\
Mold & 72 & $17.48 \%$ \\
Food allergens & 64 & $15.53 \%$ \\
Hymenoptera (bees, wasps, hornets etc.) & 34 & $8.25 \%$ \\
Latex & 25 & $6.07 \%$ \\
Cockroaches & 9 & $2.18 \%$ \\
\hline
\end{tabular}

Abbreviation: $\mathrm{n}$, number of participants.

Table 4 Skin Reactions Associated with Allergies

\begin{tabular}{|l|c|c|}
\hline & $\mathbf{n}$ & $\%$ \\
\hline $\begin{array}{l}\text { Percentage of Participants Reporting Skin } \\
\text { Reaction } \\
\text { Percentage managed by a doctor }\end{array}$ & $\mathbf{2 1 9}$ & $\mathbf{5 3 . 1 6 \%}$ \\
\hline $\begin{array}{l}\text { Who is the Health Professional Who Managed the } \\
\text { Skin Reaction? }\end{array}$ & 132 & $60.27 \%$ \\
$\begin{array}{l}\text { General practitioner } \\
\text { Dermatologist } \\
\text { Allergy specialist }\end{array}$ & 154 & $47.38 \%$ \\
\hline $\begin{array}{l}\text { Participants Reporting Prescribed } \\
\text { Treatment for Skin Reaction }\end{array}$ & 60 & $18.46 \%$ \\
\hline $\begin{array}{l}\text { What kind of treatment was prescribed for your } \\
\text { skin reaction? }\end{array}$ & $\mathbf{5 9 9}$ & $\mathbf{7 8 . 9 2 \%}$ \\
$\quad \begin{array}{l}\text { Topical } \\
\text { Oral } \\
\text { Skincare products }\end{array}$ & 48 & $63.16 \%$ \\
\hline
\end{tabular}

Abbreviation: $\mathrm{n}$, number of participants.

However, the two populations were similar in age (mean age $45 \pm 15.8$ vs $45.9 \pm 15.5$ years) and in phototype, which included light (phototypes I, II and III), $87.4 \%$ vs $88.2 \%$, respectively, and dark skin (phototypes IV, V, and VI), $12.6 \%$ vs $11.8 \%$, respectively, for the 2 populations. 
Compared to those who did not report an allergy, French respondents with allergies were 1.7 to 3.8 times more likely to also report a skin disease, including atopic dermatitis (14.6\% vs 3.8\%, p $<0.001$; RR 3.4), contact dermatitis (21.1\% vs $5.7 \%, \mathrm{p}<0.001$; RR 3.7$)$, acne ( $17.5 \%$ vs $10.3 \%$, $\mathrm{p}<0.001$ RR 1.69$)$, and psoriasis $(14.4 \%$ vs $8.3 \%, \mathrm{p}<0.01$ RR 1.2), as well as 1.5 times more likely to report sensitive skin (71.9 vs 46\%, p<0.001.; RR 1.56) (Figure 1). They more frequently reported sensitive skin, particularly very sensitive skin $(21.1$ vs $6.8 \%)(\mathrm{p}<0.0001)$, sensitive eyes (68.2 vs $45.2 \%, \mathrm{p}<0.0001$ ) and having parents with sensitive skin (34.2 vs $16 \%, \mathrm{p}<0.0001)$, and the differences were significant. Interestingly, $38.6 \%$ of those who reported allergies also reported having atopic dermatitis during childhood, versus $15.9 \%$ for those who did not report an allergy $(\mathrm{p}<0.0001)$.

Those who reported allergies were more likely to experience skin discomfort and reported a higher incidence of severe skin discomfort (Figure 2). They were also twice as likely to report $(\mathrm{p}<0.001)$ skin reactions when using skincare products (Figure 3).

\section{Environmental Impact}

The group of individuals who reported allergies was significantly more impacted by air, water, ground, noise, light and radiation pollution $(\mathrm{p}<0.0001)$ than the group of individuals who did not report an allergy (Table 5). They more frequently claimed that pollution affected their way of life (59.5 vs $39.8 \%, \mathrm{p}<0.001)$ and negatively impacted their health and well-being ( 82.5 vs $64.5 \%, \mathrm{p}<0.0001$ ). They also more commonly noted pollution's impact on their skin (32 vs $20.3 \%$, $\mathrm{p}<0.0007$, quite to very important for 41.5 vs $23.7 \%$, $\mathrm{p}<0.0001$ ), but their use of dermocosmetics to protect their skin against pollution ( $32.3 \mathrm{vs} 25 \%$ ) was similar to that in nonallergic cases.

In the group of individuals who reported allergies, slightly fewer experienced moderate and intense daylight solar exposure than in the group of individuals who did not report an allergy ( 59.5 vs $61.3 \%, \mathrm{p}<0.0001)$. In addition, only $11.9 \%$ reported not using any photoprotection, in comparison to $17.5 \%$ in the group of individuals who did not report an allergy $(\mathrm{p}<0.001)$. They similarly applied sunscreen during outdoor leisure activities (17.2 vs $29.2 \%$ ) or during intense sun exposure (57 vs $55 \%$ ) but were more likely to apply it when working outdoors ( 34.2 vs $12.9 \%, \mathrm{p}<0.03)$.

\section{Discussion}

During this investigation performed with a representative sample of the adult French population, $20.2 \%$ of

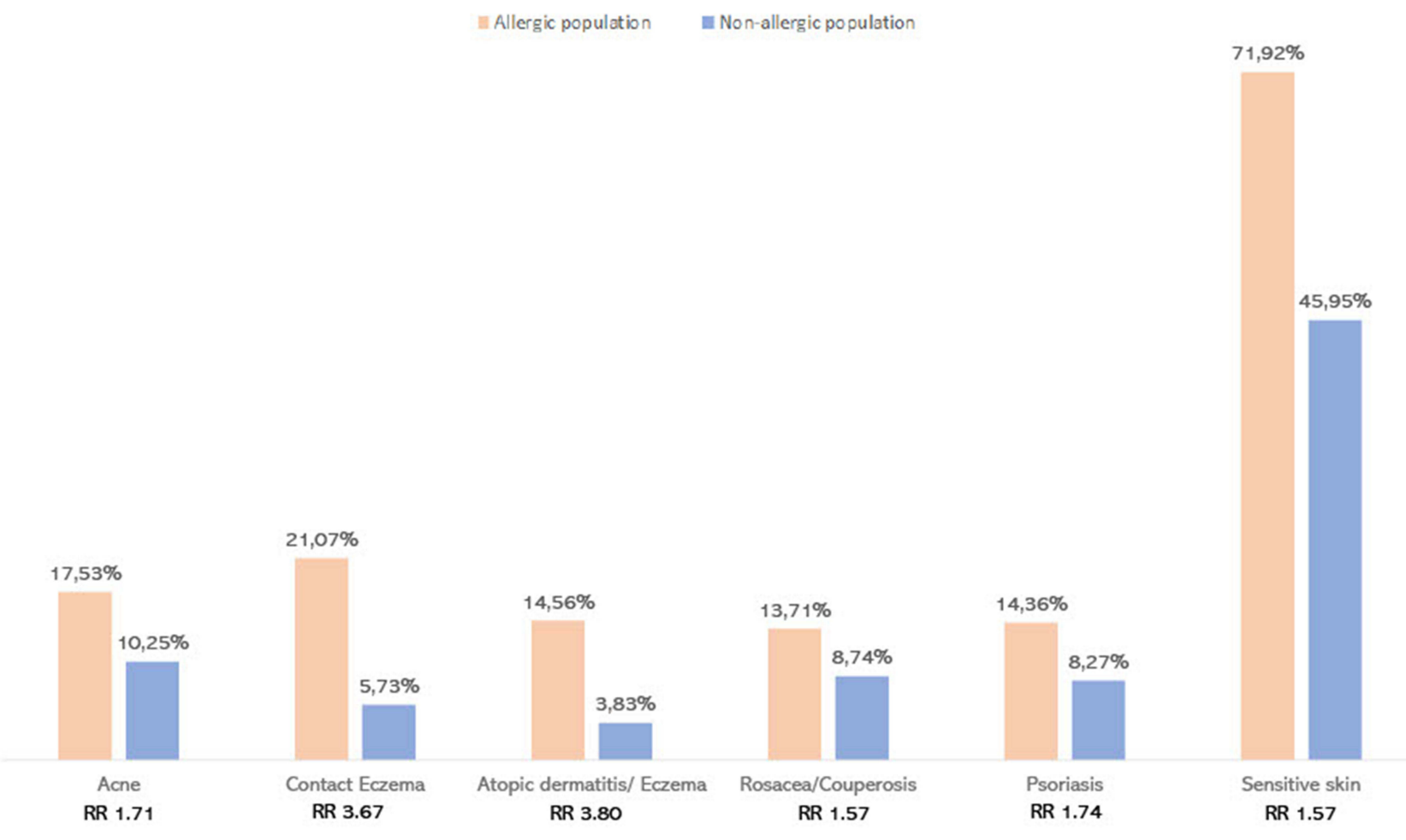

Figure I Skin diseases in the two populations. 


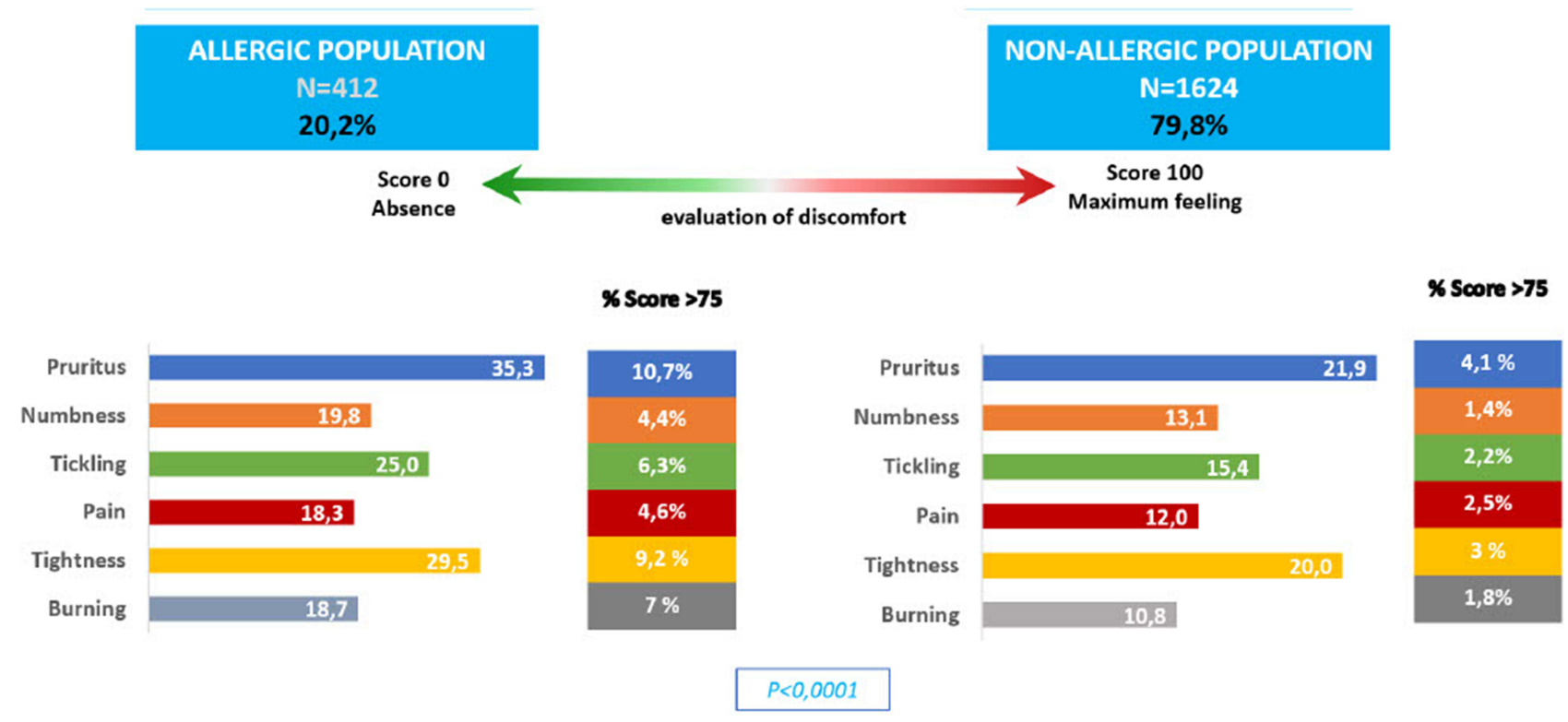

Figure 2 Skin discomforts in the two populations.

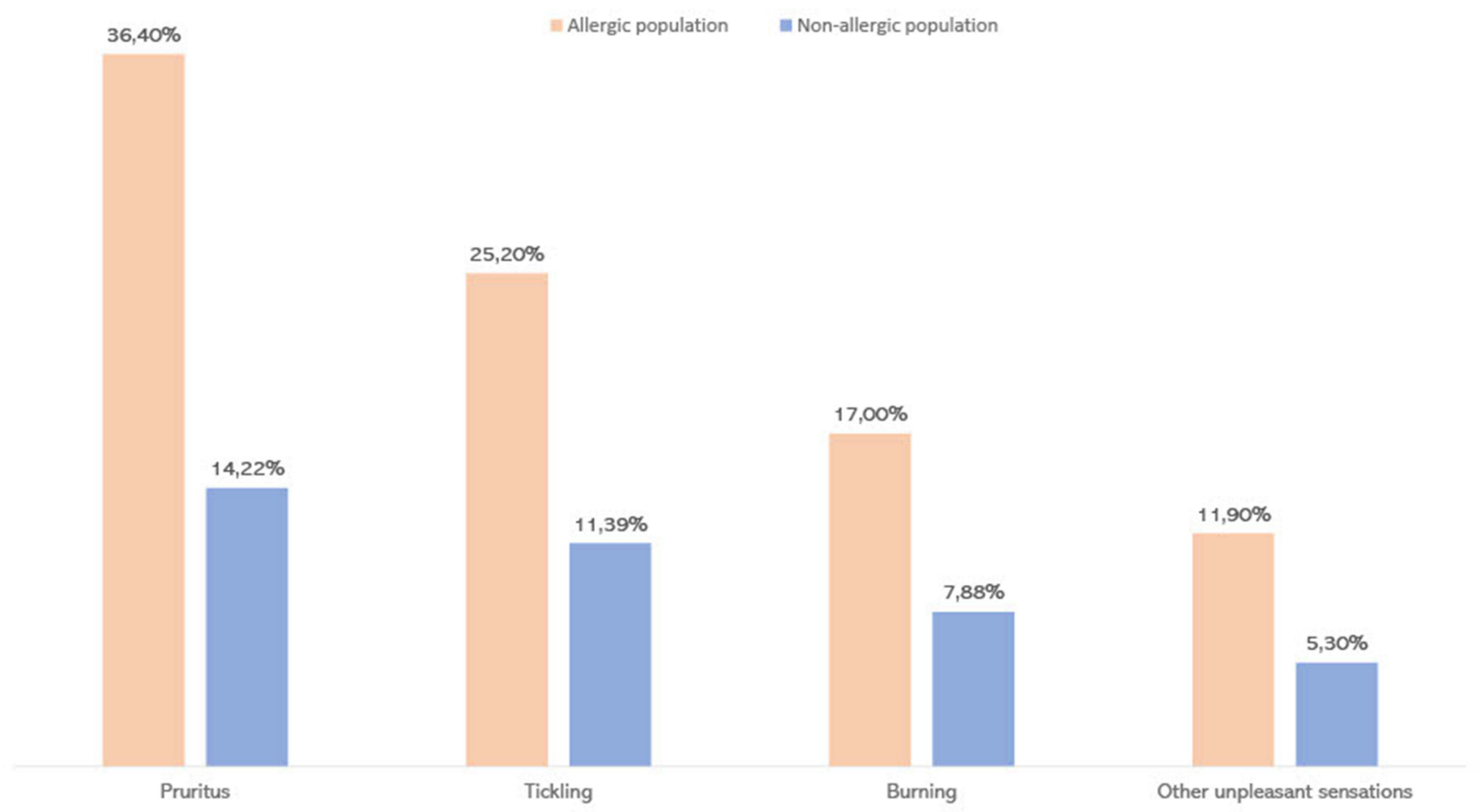

Figure 3 Skin discomforts associated with skincare products in the two populations.

respondents self-reported suffering from at least one allergy. Self-reporting is one of the limitations of this survey, although $78.9 \%$ of allergic people said that their allergies were officially diagnosed by a doctor. Nevertheless, a nonimmune adverse reaction to food may be easily misconstrued with an allergic reaction and selfreported as such. ${ }^{4}$ As most patients and even physicians consider atopic dermatitis (and many other skin diseases) to be a skin allergy, this creates bias and should be considered a limitation. Another limitation of this study is that only adults 18 years of age and older were questioned, whereas allergy rates are increasing most rapidly in the younger generations. ${ }^{5}$ Interestingly, stabilization is currently being observed. 
Table 5 Impact of Pollution in the Two Populations

\begin{tabular}{|c|c|c|c|c|c|c|}
\hline & \multicolumn{3}{|c|}{ Impacted } & \multicolumn{3}{|c|}{ Worried } \\
\hline & Allergic $n=412$ & Non-Allergic $n=1624$ & $\mathbf{R R}$ & Allergic $n=412$ & Non-Allergic $n=1624$ & $\mathbf{R R}$ \\
\hline Air & $77.4 \%$ & $65.02 \%$ & 1.19 & $57.04 \%$ & $53.5 \%$ & 1.07 \\
\hline Water & $23.1 \%$ & $16.32 \%$ & $1.4 \mathrm{I}$ & $9.95 \%$ & $10.6 \%$ & 0.94 \\
\hline Soil & $14.6 \%$ & $8.50 \%$ & 1.71 & $3.16 \%$ & $3.6 \%$ & 0.88 \\
\hline Noise & $45.9 \%$ & $33.99 \%$ & 1.35 & $8.25 \%$ & $7.7 \%$ & 1.07 \\
\hline Light & $27.2 \%$ & $15.15 \%$ & 1.79 & $2.91 \%$ & $2.0 \%$ & 1.48 \\
\hline Radiation & $33.7 \%$ & $21.80 \%$ & 1.55 & $13.59 \%$ & $11.4 \%$ & 1.19 \\
\hline
\end{tabular}

Abbreviation: $n$, number of participants.

Few data on allergies in the French population are available. A recent study assessed the risk of allergic disease among 714 children of the Paris birth cohort, consisting of 3840 full-term and healthy singletons born from parents living in Paris or nearby suburbs. ${ }^{6}$ In this study, a profile of early and transient sensitization to foods that increased the risk of asthma later in childhood was identified (4.9\%). Children strongly sensitized to house dust mites at 8 to 9 years of age $(9.0 \%)$ had the highest risks of asthma and allergic rhinitis. Finally, the sensitization profile for timothy grass pollen at $8 / 9$ years of age $(5.3 \%)$ was related to respiratory allergic diseases, as was early onset and a persistent sensitization profile (4.1\%), the latter being strongly associated with atopic dermatitis.

Many theories have been developed to explain the ongoing increase in allergy prevalence worldwide. The role of the skin barrier in allergic sensitization has been well described; in particular, skin barrier dysfunction can trigger sensitization by increasing the likelihood of allergens that come into contact with the immune system. ${ }^{7}$ Nevertheless, the impact of some skin conditions, such as $\mathrm{AD}$, has been well studied. In contrast, the impacts of allergies on skin conditions have not been clearly evidenced. Interestingly, our results show a clear association between any type of allergy and skin disease or skin sensitivity. ${ }^{8}$

French patients may find some difficulty in accessing an allergist practitioner and receiving an allergy work-up. ${ }^{9}$ Better knowledge of allergies is critical for providing the best care to a great number of French people suffering from these symptoms. For a great number of allergic people, respiratory, food, and skin allergy symptoms create a significant burden through anxiety, relationship degradation, embarrassment, and frequent disturbances of normal tasks, all contributing to a poorer quality of life. ${ }^{10-12}$
For example, despite international guidelines, so-called dermatological allergies are treated with oral corticosteroids in $13.4 \%$ of cases and with topical corticosteroids in $59.8 \%$ of this population, which is the majority of patients. ${ }^{13}$

Regarding environmental impact, the skin's immune system may be disturbed by exposure to chemicals that may interfere with inflammatory reactions. ${ }^{14}$ Furthermore, there are some genetic predispositions that can promote responses to pollutants that particularly impact the skin, and patients with $\mathrm{AD}$ are more sensitive to air pollution than others. ${ }^{15}$ Nevertheless, non-atopic people can also feel the effects of pollution, especially elderly women. ${ }^{16}$ It has already been shown that patients with eczema feel that pollution has an aggravating effect on their skin. Some of the symptoms described in this survey have been demonstrated to be enhanced by contact with chemicals, especially by air pollutants with indoor and/or outdoor origins. $^{17}$

There is also a link between air pollution, AD flare levels and increased skin sensitivity. ${ }^{18}$ In addition, climate warming can enhance air pollution, increasing its impact on human health and clinical features, as described in our population. ${ }^{19}$

Further studies are required to develop new strategies to manage allergies. Lower exposure to allergens can be helpful, and $55.3 \%$ of the surveyed French respondents were able to identify the causative allergens. We have evaluated the importance of these allergic diseases in a European country. In recent years, the incidence of allergies has stabilized, ${ }^{20}$ but as demonstrated in our study, the incidence remains very high. Multiple approaches are necessary to improve the quality of life of these patients and better understand the links between allergies and environmental factors. 


\section{Acknowledgments}

The authors acknowledge the great technical support of G. Le Dantec and M. Fortuné.

\section{Author Contributions}

All authors made a significant contribution to the work reported, whether that is in the conception, study design, execution, acquisition of data, analysis and interpretation, or in all these areas; took part in drafting, revising or critically reviewing the article; gave final approval of the version to be published; have agreed on the journal to which the article has been submitted; and agree to be accountable for all aspects of the work.

\section{Funding}

This work was supported by La Roche-Posay Dermatological Laboratories, France.

\section{Disclosure}

S. Seité is an employee of La Roche-Posay, France. C. Taieb, Nhân Pham-Thi and A. Barbaud have served as consultants for L'Oreal/La Roche-Posay. The authors report no other conflicts of interest in this work.

\section{References}

1. Okada H, Kuhn C, Feillet H, Bach JF. The 'hygiene hypothesis' for autoimmune and allergic diseases: an update. Clin Exp Immunol. 2010;160(1):1-9. doi:10.1111/j.1365-2249.2010.04139.x

2. Clark H, Granell R, Curtin JA, et al. Differential associations of allergic disease genetic variants with developmental profiles of eczema, wheeze and rhinitis. Clin Exp Allergy. 2019;49 (11):1475-1486. doi:10.1111/cea.13485

3. Puri P, Nandar SK, Kathuria S, Ramesh V. Effects of air pollution on the skin: a review. Indian J Dermatol Venereol Leprol. 2017;83 (4):415-423. doi:10.4103/0378-6323.199579

4. Sicherer SH. Epidemiology of food allergy. J Allergy Clin Immunol. 2011;127(3):594-602. doi:10.1016/j.jaci.2010.11.044

5. Jackson KD, Howie LD, Akinbami LJ. Trends in allergic conditions among children: United States, 1997-2011. NCHS Data Brief. 2013;121:1-8. PMID: 23742874.

6. Gabet S, Rancière F, Just $\mathrm{J}$, et al. Asthma and allergic rhinitis risk depends on house dust mite specific IgE levels in PARIS birth cohort children. World Allergy Organ J. 2019;12(9):100057. doi:10.1016/j. waojou.2019.100057
7. Strugar TL, Kuo A, Seite S, Lin M, Lio P. Connecting the dots: from skin barrier dysfunction to allergic sensitization, and the role of moisturizers in repairing the skin barrier. $J$ Drugs Dermatol. 2019;18(6):5.

8. Bergmann MM, Caubet JC, Boguniewicz M, Eigenmann PA. Evaluation of food allergy in patients with atopic dermatitis. J Allergy Clin Immunol Pract. 2013;1(1):22-28. doi:10.1016/j.jaip. 2012.11.005

9. Fyhrquist N, Werfel T, Bilò MB, Mülleneisen N, Gerth van Wijk R. The roadmap for the Allergology specialty and allergy care in Europe and adjacent countries. An EAACI position paper. Clin Transl Allergy. 2019;9:3. doi:10.1186/s13601-019-0245-z

10. Schmier JK, Chan KS, Leidy NK. The impact of asthma on health-related quality of life. $J$ Asthma. 1998;35(7):585-597. doi:10.3109/02770909809048961

11. Bacal LR. The impact of food allergies on quality of life. Pediatr Ann. 2013;42(7):141-145. doi:10.3928/00904481-20130 619-12

12. Kalboussi $\mathrm{H}$, Kacem I, Aroui $\mathrm{H}$, et al. Impact of allergic contact dermatitis on the quality of life and work productivity. Dermatol Res Pract. 2019;2019:3797536. doi:10.1155/ 2019/3797536

13. Wollenberg A, Barbarot S, Bieber T, et al. Consensus-based European guidelines for treatment of atopic eczema (atopic dermatitis) in adults and children. J Eur Acad Dermatol Venereol. 2018;32 (6):850-878. doi:10.1111/jdv.14888

14. Dong YM, Liao LY, Li L, et al. Skin inflammation induced by ambient particulate matter in China. Sci Total Environ. 2019;68 2:364-373. doi:10.1016/j.scitotenv.2019.05.155

15. Hüls A, Klümper C, MacIntyre EA, et al. Atopic dermatitis: interaction between genetic variants of GSTP1, TNF, TLR2, and TLR4 and air pollution in early life. Pediatr Allergy Immunol. 2018;29 (6):596-605. doi:10.1111/pai.12903

16. Hüls A, Abramson MJ, Sugiri D, et al. Nonatopic eczema in elderly women: effect of air pollution and genes. J Allergy Clin Immunol. 2019;143:378-385. doi:10.1016/j.jaci.2018.09.031

17. Norbäck D, Lu C, Zhang Y, et al. Sources of indoor particulate matter (PM) and outdoor air pollution in China in relation to asthma, wheeze, rhinitis and eczema among pre-school children: synergistic effects between antibiotics use and PM 10 and second hand smoke. Environ Int. 2019;125:252-260. doi:10.1016/j.envint. 2019.01 .036

18. Krutmann J, Liu W, Li L, et al. Pollution and skin: from epidemiological and mechanistic studies to clinical implications. J Dermatol Sci. 2014;76(3):163-168. PMID: 25278222. doi:10.1016/j.jdermsci. 2014.08.008.

19. Kathuria P, Silverberg JI. Association of pollution and climate with atopic eczema in US children. Pediatr Allergy Immunol. 2016;27 (5):478-485. doi:10.1111/pai.12543

20. Tang ML, Mullins RJ. Food allergy: is prevalence increasing? Intern Med J. 2017;47(3):256-261. doi:10.1111/imj.13362
Clinical, Cosmetic and Investigational Dermatology

\section{Publish your work in this journal}

Clinical, Cosmetic and Investigational Dermatology is an international, peer-reviewed, open access, online journal that focuses on the latest clinical and experimental research in all aspects of skin disease and cosmetic interventions. This journal is indexed on CAS
The manuscript management system is completely online and includes a very quick and fair peer-review system, which is all easy to use. Visit http://www.dovepress.com/testimonials.php to read real quotes from published authors. 